\title{
MIRNAPIS INCA, GÊNERO E ESPÉCIE NOVOS DE EUCERINAE DA AMÉRICA DO SUL (HYMENOPTERA, APOIDEA, ANTHOPHORIDAE) ${ }^{1}$
}

\author{
Danúncia Urban ${ }^{2}$
}

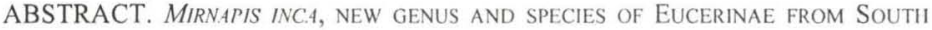
AMERICA (HYMENOPTERA, APOIDEA, ANTHOPHORIDAE). Mirnapis gen.n. is proposed to a Peruvian species of Eucerinae, with gradular tooth on each side of the sixth tergum, lanceolate hairs in the ventral face of the middle tibia, pygidial plate narrowed apically and the apex of the valvae genitalia of the male with peculiar shape.

KEY WORDS. Apoidea, Anthophoridae, Eucerinae, Mirnapis gen.n., taxonomy.
\end{abstract}

MOURE \& MiCHENER (1955) publicaram um trabalho básico para o estudo dos Eucerinae Neotropicais, onde redescrevem os gêneros conhecidos e propõem gêneros novos; posteriormente, foram dados a conhecer mais três gêneros sulamericanos, Platysvastra Moure, 1967, Hamatothrix Urban, 1989 e Santiago Urban, 1989. Foram comparados exemplares dos gêneros de Eucerinae com os estudados neste trabalho e resultou na proposta de Mirnapis como gênero novo, cujos machos são caracterizados pelas projeções dentiformes agudas nos lados do sexto tergo; parte da face ventral das tíbias medianas com pêlos curtos lanceolados; placa pigidial com o ápice estreito e arredondado; placas laterais do sétimo esterno com o bordo externo sinuado; gonóstilos não capitados e com cerdas finas, valvas com o ápice em lâmina arredondada ou levemente acuminada; pilosidade longa e fina nos tergos.

Este gênero compartilha com Gaesischia e Svastrides descritos por MicHENER et al. (1955), os palpos maxilares penta-articulados, flagelômero basal curto, carena látero-clipeal forte e clípeo afastado dos olhos.

\section{Mirnapis gen.n.}

Espécie tipo: Mirnapis inca sp.n.

Cabeça mais larga que longa (Fig. 1); clípeo abaulado, protuberante, separado dos olhos na altura dos ângulos laterais por uma distância menor que a metade do diâmetro mínimo do flagelômero basal, micro-reticulado e fosco, com pontos rasos; área supraclipeal micro-reticulada quase fosca. Carena frontal curta, entre as antenas; carenas paroculares não chegando ao topo dos olhos nem às proximidades do clípeo; alvéolos antenais mais afastados entre si do que dos olhos; genas de perfil,

1) Contribuição número 1014 do Departamento de Zoologia, Universidade Federal do Paraná.

2) Departamento de Zoologia, Universidade Federal do Paraná. Caixa Postal 19020, 81531-990 Curitiba, Paraná, Brasil. Bolsista do CNPq. 
quase o dobro da largura dos olhos; comprimento mínimo da área malar igualando um terço da largura da base da mandibula; comprimento mínimo do primeiro flagelômero um sexto do mínimo do segundo flagelômero e o tamanho máximo do primeiro pouco menor que um quarto do máximo do segundo; diâmetro do quarto flagelômero igual a um terço do seu comprimento; labro com recorte apical anguloso, seu comprimento, na linha média, aproximadamente a metade da largura da base; palpos maxilares com cinco artículos. Asas anteriores com a segunda célula sub-marginal quadrangular, o Rs e o primeiro $\mathrm{r}-\mathrm{m}$ quase paralelos; primeiro ramo de $\mathbf{m}$-cu anterior ao primeiro $\mathbf{r}-\mathbf{m}$, por uma distância maior que dois diâmetros da veia.
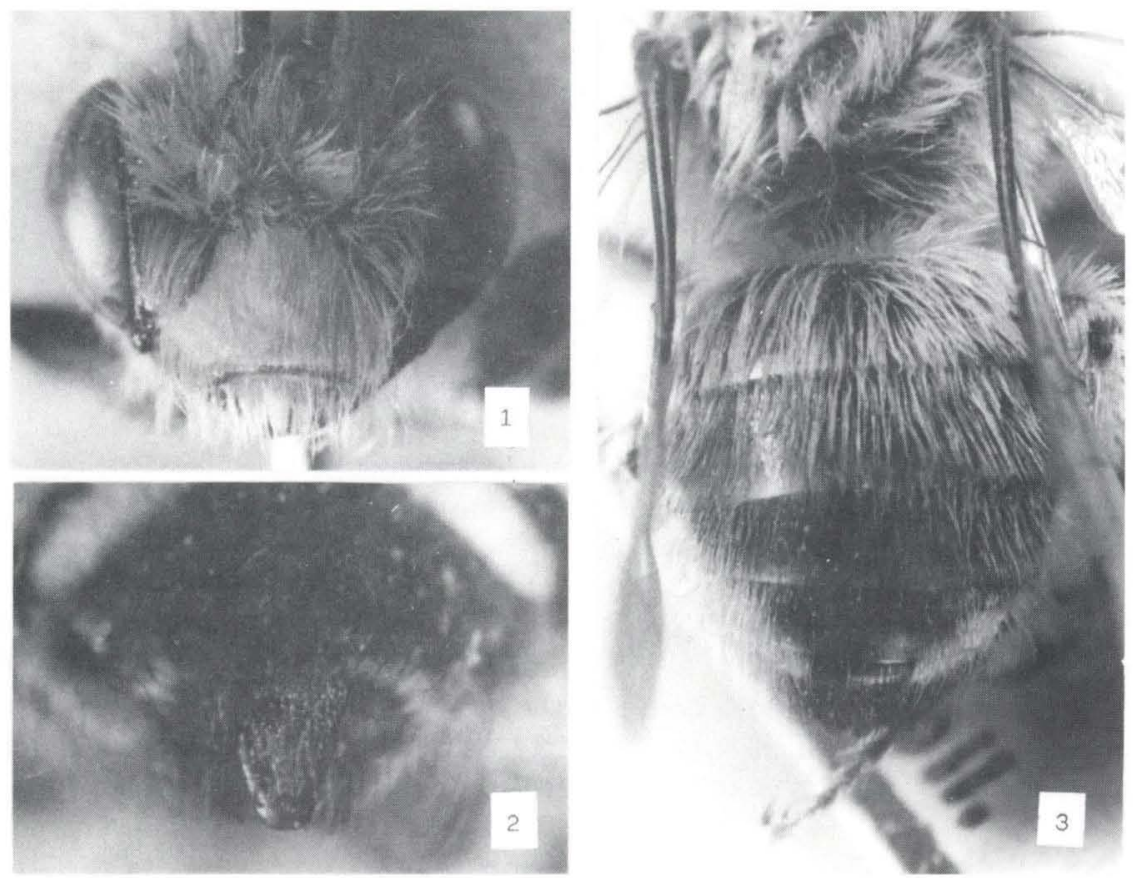

Figs 1-3. Mirnapis inca sp.n., parátipo. (1) Cabeça; (2) tergos distais e placa pigidial; (3) ápice do mesosoma e tergos.

Quatro tergos basais com margem lisa larga, mais larga que um diâmetro de ocelo, um pouco mais estreita no quinto, com pontos esparsos para o disco; sexto tergo com dentes gradulares angulosos projetados para trás; sétimo tergo sem dentes laterais; placa pigidial distalmente arredondada quase igualando um diâmetro de ocelo no ápice, sem recortes subapicais, os bordos laminados e elevados quase até a base (Fig. 2); sexto esterno fracamente canaliculado e com cerdas curtas medianamente; com duas carenas laminadas, paralelas aos bordos laterais e amplamente separadas no meio; sétimo esterno com as placas laterais ovaladas, o bordo externo levemente sinuado, sem chanfro, as placas médias dobradas, não alargadas distal- 
mente, com pêlos esparsos (Figs 6-7); genitália com os gonóstilos delgados, com pêlos finos e lisos; também com pêlos finos na base, ventralmente; ápice das valvas laminado-foliáceo, de contorno apical arredondado (Figs 4-5), em um dos parátipos levemente acuminado

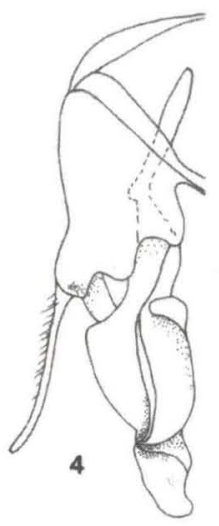

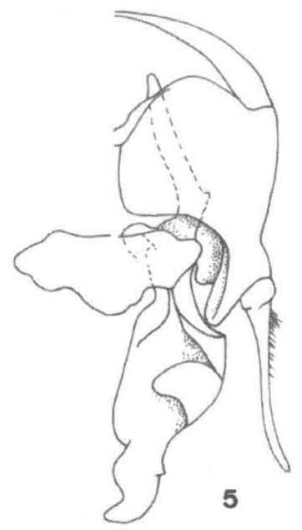
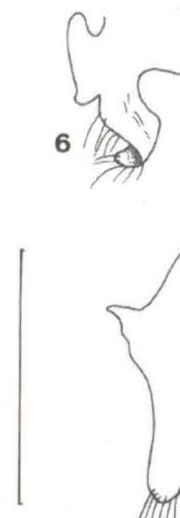
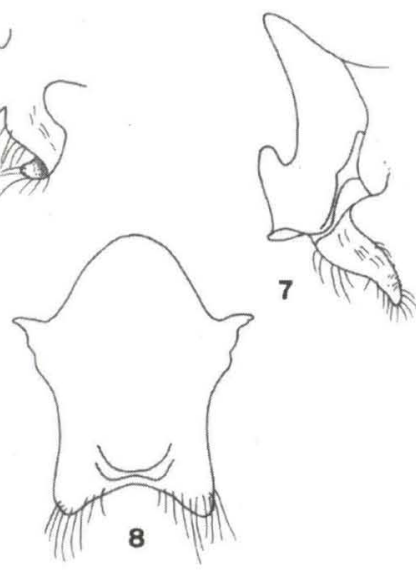

Figs 4-8. Mirnapis inca sp.n., parátipo. (4) Genitália em vista ventral, metade esquerda; (5) genitália em vista dorsal, metade direita, com a espata completa; (6) sétimo esterno, vista dorsal das placas média e lateral; (7) sétimo esterno, vista ventral da metade esquerda, com a placa média desdobrada; (8) oitavo esterno.

Pilosidade longa e fina do tergo basal ao quinto, quase tão longa como o tergo ou até ultrapassando o comprimento do mesmo, porém não densa, deixando ver claramente o tegumento (Fig. 3). Tíbias medianas com pêlos lanceolados curtos, decumbentes e voltados obliquamente para trás, revestindo densamente uma área alongada na face ventral, do meio da tíbia às proximidades do esporão, diferenciada da pilosidade longa adjacente.

Comentário. Na chave para os machos de Eucerini, elaborada por MOURE \& MiCHENER (1955), Mirnapis chegaria ao item 27 juntamente com Svastrides e Gaesischia.

Svastrides é reconhecido pelas carenas paroculares separadas das látero-clipeais; área malar estreita, no máximo medindo um terço da largura da mandíbula na base; face ventral das tíbias medianas com área revestida de pêlos espatulados, os pêlos dispostos transversalmente, da face anterior para a posterior; pilosidade alongada no segundo e terceiro tergos, sem faixa de pêlos claros densos e curtos; sexto tergo com o grádulo expandido lateralmente em lamelas arredondadas; placa pigidial larga distalmente, igualando dois diâmetros de ocelo e com os bordos paralelos na área apical passando a divergentes para a base; sétimo esterno com as placas laterais recortadas no bordo externo; valvas da genitália com ápice agudo, pêlos grossos e ramificados nos gonóstilos.

Em Gaesischia, as carenas paroculares são contínuas com as látero-clipeais, ou ambas ligadas por carena baixa; área malar muito curta, quase linear; tíbias 
medianas com pilosidade curta ou alongada, sem área revestida com pêlos lanceolados na face ventral; segundo e terceiro tergos geralmente com pilosidade branca ou amarela, densa e curta, formando faixa ou revestindo quase todo o tergo; placa pigidial com os bordos divergentes, o ápice mais largo que um diâmetro de ocelo; sexto tergo, sétimo esterno e valvas da genitália como citados acima para Svastrides; gonóstilos com pêlos finos.

Santiago, outro gênero que se insere no ítem 27 da referida chave, distinguese de Mirnapis pela área malar muito curta, placa pigidial larga e truncada distalmente, pilosidade muito curta nos tergos, carenas do sexto esterno curtas e um pouco sinuadas, placas laterais do sétimo esterno com recorte no lado externo. Tem em comum com Mirnapis as projeções dentiformes agudas nos lados do sexto tergo e as carenas paroculares não alcançando as carenas látero-clipeais.

O nome do gênero é uma homenagem à Profa Dra Mirna Martins Casagrande por sua dedicação às pesquisas sobre os Lepidoptera.

\section{Mirnapis inca sp.n.}

Figs 1-8

Diagnose. Macho com labro e clípeo amarelos; pilosidade branca a amarelo-acastanhada pálida, longa nos tergos e com pequenas faixas laterais denso-plumosas brancas no quarto e quinto tergos.

Holótipo macho. Tegumento preto com labro e clípeo amarelo-esbranquiçados, o clípeo castanho no ápice e preto junto à sutura epistomal; mandíbulas com nódoa subapical alongada amarela; antenas castanho-amareladas ventralmente, do segundo flagelômero ao apical; tégulas castanho-amareladas; tarsômeros castanhos; primeiro ao quarto tergo com margem translúcida esbranquiçada; esternos castanhos.

Pilosidade branca na cabeça, levemente amarelada na fronte, paroculares superiores e vértice; amarelo-acastanhada pálida no dorso do mesosoma e metade dorsal dos mesepisternos, restante dos mesepisternos e pernas com pêlos brancos; face interna das tíbias medianas com pêlos lanceolados castanhos, decumbentes, inclinados para trás, estes pêlos ocupando área menor que a que a metade da tíbia; lado ventral dos tarsômeros com cerdas castanho-amareladas; branca e longa nos três tergos basais, com pêlos pretos longos e esparsos no meio do segundo, mais numerosos do terceiro ao quinto tergo; quarto e quinto tergos com pêlos brancos longos na base, tão longos como o tergo, e faixas brancas laterais de pêlos decumbentes, curtos e denso-plumosos; no sexto castanha, pouco mais curta que nos tergos anteriores, com pequena área branco-pilosa nos flancos; castanha no sétimo; branca nos esternos, formando franja do segundo ao quarto, a franja mais estreita no meio; castanha nos dois distais.

Comprimento aproximado $10,85 \mathrm{~mm}$; comprimento da asa anterior a partir do esclerito costal $9,07 \mathrm{~mm}$; largura da cabeça $3,80 \mathrm{~mm}$; comprimento do olho 2,0 $\mathrm{mm}$; distância interorbital superior $2,54 \mathrm{~mm}$ e a inferior $2,30 \mathrm{~mm}$; comprimento máximo do segundo e terceiro flagelômeros $1,30 \mathrm{~mm}$ e $0,94 \mathrm{~mm}$. 
Holótipo macho. Peru, Arequipa: 2.200m, III.1954, A. Meza coll., cinco parátipos com os mesmos dados. Os tipos encontram-se depositados na Coleção de Entomologia Pe. J.S. Moure, Departamento de Zoologia, Universidade Federal do Paraná, Curitiba, com exceção de um parátipo no Snow Entomological Museum, University of Kansas, Lawrence.

Distribuição geográfica. PERU, Arequipa.

Etimologia. O nome é alusivo à antiga dinastia peruana.

AGRADECIMENTOS. A autora agradece ao Prof. Dr. Albino Morimasa Sakakibara pelas fotos que ilustram o trabalho.

\section{REFERÊNCIAS BIBLIOGRÁFICAS}

Michener, C.D.; W.E. Laberge \& J.S. Moure. 1955. Some American Eucerini Bees. Dusenia 6 (6): 213-230.

Moure, J.S. 1967. A New Genus and two New Species of Eucerine Bees from South America (Hymenoptera, Apoidea). Dusenia 7 (5): 147-152.

MOURE, J.S. \& C.D. MiCHENER. 1955. A contribution toward the Classification of Neotropical Eucerini (Hymenoptera, Apoidea). Dusenia 6 (6): 239-331.

Urban, D. 1989. Dois gêneros novos de Eucerinae Neotropicais (Hymenoptera, Apoidea). Revta bras. Zool. 6 (1): 117-124.

Recebido em 27.III.1997; aceito em 03.IX.1997. 